\title{
Urgences
}

\section{Défoulement d'un retraité (extraits de " Propos et Confidences d'un vieux Maître d'École ")}

\section{Charles-Aimé Poirier}

Numéro 2, 3e trimestre 1981

URI : https://id.erudit.org/iderudit/025028ar

DOI : https://doi.org/10.7202/025028ar

Aller au sommaire du numéro

Éditeur(s)

Urgences

ISSN

0226-9554 (imprimé)

1927-3924 (numérique)

Découvrir la revue

Citer ce document

Poirier, C.-A. (1981). Défoulement d'un retraité (extraits de " Propos et

Confidences d'un vieux Maître d'École "). Urgences, (2), 51-55.

https://doi.org/10.7202/025028ar d'utilisation que vous pouvez consulter en ligne.

https://apropos.erudit.org/fr/usagers/politique-dutilisation/ 


\section{CHARLES-AIMÉ POIRIER}

\section{Défoulement d'un retraité}

(Extrait de "Propos et Confidences

d'un vieux Maître d'École") 


\section{(A mon Alma Mater "occupée"...)}

"O nostalgie d'un passé qui disparait, quand tu nous tiens!"

Aujourd'hui, la fête de la Saint-Charles, celle de mon patron et aussi de mon Alma Mater. Donc je décide d'un petit voyage au pays de mon enfance, puis à celui de mon adolescence. A la retraite, il arrive qu'on ait de ces fantaisies. Depuis que la société besogneuse m'a exclu de son sein tout en me gratifiant de 24 heures par jour de disponibilité, j'ai certes "le temps de perdre du temps", voire de jongler, sinon avec des idées, du moins avec des souvenirs.

Comme tous les "retirés" du monde, je suis comme submergé, tout vivant, par le ressac des souvenirs. Cette retraite, ce "nouveau retour à l'enfance de son âge" me donne donc l'occasion de visionner, au moins en diagonale, le film héroïcomique de ma modeste et montante vie. C'est incroyable tout ce qu'on peut entasser de choses, pêle-mêle, au cours des ans, dans la mémoire et la subconscience, entre autres, les souvenirs d'enfance si fortement ancrés et d'une façon indélibile en chacun de nous.

Malheureusement pour moi, cancre, hère et pauvre diable, n'étant pas "une personnalité du mois" ou de l'année, ni même le professeur Barbeau ou le Père Legault, personne ne songe à m'interviewer. Ça ne m'empêche pas de me poser, quand j'parle tout seul, les sempiternelles questions: quels sont vos ascendances?... où êtes-vous né?... où avez-vous fait vos études?... Comme si cela pouvait encore de nos jours intéresser les autres. Or, il parait que oui. Je me dévouerai done s'il le faut, et voici (du moins pour la postérité) mon interview (non sollicitée).

Primo, moi, monsieur (ou madame), je vous ferai d'abord remarquer que, toujours hanté par les sommets, je ne descends jamais, je monte... Je ne descends pas d'une noble lignée, mais je monte de rien ou presque. Même que j'existe, quoi qu'on en pense ça et là. La preuve?... J'écris, je noircis 
deux à trois pages par jour, donc je pense. Et si je pense, je suis, "cogito, ergo sum", Cartesianus dixit.

Secundo, je suis né dans un coin de pays de la Haute-Gaspésie, un patelin qui, comme tant d'autres St-Paulin, est aujourd'hui disparu. J'ai souvenance qu'il s'appelait jadis Sandy-Bay. Vous doutez?... Cherchez, pour voir, "Sandy-Bay", sur la mappe ou dans n'importe quel dépliant touristique. Rien, plus rien. Mème que la somptueuse, l'incomparable église de mon baptême et de mes premiers Noëls d'enfant est disparue un soir d'hiver dans la fumée. La maison natale où j'ai fait mes premiers pas, pris mes premiers ébats, et toutes les bâtisses qui dominaient la ferme ancestrale, tout cela est bel et bien disparu. Ma famille - je pense que nous étions pas moins de 16 frères et soeurs, à nous tout seuls - elle aussi, éparpillée par la tornade industrielle aux quatre vents du vaste monde. C'est bien évident, je suis un authentique déporté, tout comme les Acadiens de Grand-Pré, mes lointains et infortunés ancêtres, un apatride par atavisme, une sorte de Canadien errant, peut-être au fond un "grand oublié" de la petite histoire. C'est que la ville enjôleuse, exploitant notre sacrée soif de l'or (auri sacra fames), cette ville-mirage nous a tout pris, même la terre paternelle, la "terra patria", le sol natal sans quoi la patrie n'est point. René Bazin avait eu raison d'écrire: "La terre qui meurt...". Je me souviens qu'à la petite école du rang Tartigou, elle aussi disparue, notre institutrice, Berthe Pineault, nous faisait lire et apprendre par coeur cette phrase marquée au coin d'une profonde philosophie: "À la campagne, la vie est moins dorée, mais on y trouve le bonheur".

Tertio, je dois vous dire que, tout vagabond que je fus, tout hippie-retraité que je suis, j'ai des lettres, faute d'esprit, de talent. Jeune, étant fort peu débrouillard pour les travaux complexes de la ferme, de plus tiraillé par la "vocation", cet implacable appel de tout "adolescent sérieux", appel qui ouvre et... ferme tant de portes sur l'avenir, je dus m" universifier" par le commencement, faire, comme tous les "appelés" de ce temps-là, mon classique. Mon père d'ailleurs, en bon psychologue pratique, avait dit un soir, à voix basse, à ma mère: "Tu sais, celui-là, y'est moins intelligent que les autres 
de la famille; il va falloir le faire instruire, l'envoyer au séminaire; qui sait, il fera peut-être un curé..." Et c'est ainsi que le p'tit gars de Sandy-Bay fit un jour sa valise et, drapé dans sa belle redingote bleu marine à nervures blanches, ceinturon vert aux reins, casquette cosaque à l'avenant, fier comme Artaban, monta tout de go dans les "gros chars" vers un pays loin, loin, loin... Et moi qui avais pensé, depuis mon tendre jeune âge, que le monde s'estompait, à l'ouest quelque part à Mont-Joli et, à l'est, certainement pas plus bas que Matane... D'ailleurs, quand tu viens d'un pays aussi inconnu que SandyBay, t'as ben des excuses de ne pas être précoce en géographie, pas vrai?... T'as ben des excuses en tout cas de ne pas connaître cette "terre promise" au bout de mon premier long voyage: RIMOUSKI. Rimouski - du moins dans ce temps-là on l'affirmait sans fausse modestie et avec conviction chauvine - c'était queuqu'chose, c'était... "la Ville-Lumière du Bas-du-Fleuve", Paris n'ayant jamais existé si ce n'est dans les livres-fiction de Jules Verne.

Eh bien oui, voyez-vous ça, au début des années trente, parti de rien et sans le sou, j'arrimai presque sain et sauf sur une autre planète, à ce point géométrique zéro, le Séminaire de Rimouski, là où tout unaréopage de savants curés, relativement détachés des réalités d'ici-bas et absolument dévoués à la génération montante, couvaient toute une pléiade d'adolescents boutonneux - comme moi - dans l'unique perspective d'en faire éclore bon nombre de cleres, de religieux, de missionnaires.

Il arrivait, certains soirs, qu'on convoqua les 400 pensionnaires à la "Salle Académique" pour leur offrir tantôt un concert (décolleté) d'Anna Malenfant ou une pièce de théâtremaison faussement mixte, tantôt une conférence ou mieux une pieuse et docte cabale sur la "vocation". La vocation!... comme ce mot m'a à la fois emballé et torturé. Comme nous étions alors à l'étude du grec et du latin, nul d'entre nous n'ignorait qu'un tel vocable ne pouvait que désigner un appel sans appel d'En-Haut, une sorte de "chemin montant, sablonneux, malaisé" dont il ne fallait surtout pas s'écarter si on voulait pouvoir jeter l'ancre un jour au bon port de l'éternité; en bref et en clair, c'était la voie stoïque et héroïque des anges asexués, voie strictement interdite à la gent féminine, 
y compris bien sûr les péripatéticiennes d'occasion. C"était bien beau, courageux, magnanime, mais d'aucuns, dont moi, cherchèrent ailleurs, probablement en guise de compensation, d'autre sentiers plus battus, d'autres vocations, sinon aussi nobles, assurément moins frustrantes. Il paraît qu'il existe comme ça - et c'est un clerc spirituel qui me l'a dit - des "vocations temporaires qui nous acheminent, avec l'âge, vers la définitive". C'est ainsi que pour ma part j'aboutis cahincaha à la carrière d'éducateur qui, avant le Rapport Parent, était considérée comme "une véritable vocation", presque un sacerdoce; toujours est-il que, "ô felix culpa", cette erreur de parcours, je veux dire "ma première vocation", fut à l'origine de mon insertion définitive dans ce qu'on appelait alors "l'élite de demain".

Malgré tout, je ne voudrais pas dans ce voyage introspectif autour de ma tête, paraître un ingrat, bien au contraire. Il paraît que de nos jours ça existe encore l'ingratitude et que, dans certaines âmes boueuses, elle pousse plus facilement que la reconnaissance. Volontiers, je dois admettre, selon toute justice, que le peu que je suis devenu et que je suis, je le dois à mes maîtres, à mon Alma Mater et aussi à ce mot magique, tout plein de cet enthousiasme juvénile dont on se nourrit toute une vie, à ce mot dynamique de "Vocation"...

Voilà le genre de réflexion qui aujourd'hui trottait dans ma tête, un peu blanchie par plus de trente-cinq années d'enseignement, à l'occasion de la fête de Saint-Charles Borromée, fête dite des Anciens, alors que j'errais solitaire et pensif sur les terrains enneigés du Séminaire devenu Cégep. Je voudrais une dernière fois - j'espère que les cégépiens n'y mettront pas trop d'obstacles - la saluer, cette chère vieille Alma Mater "occupée" et, à travers elle, tous ces anciens maîtres et confrères que j'ai connus et aimés.

Aujourd'hui, si tout disparaît, le souvenir reste, c'est toujours ça de sauvé, pas vrai?... C.Q.F.D.

4 novembre 1978.

(Un ancien du Séminaire de Rimouski) 